\title{
Spacing of Toes Reveals Rheumatoid Nodulosis
}

CLÉMENT PRATI, MD, University Hospital, Rheumatology; BENOIT BARBIER BRION, MD, St. Vincent's Clinic, Radiology; GRÉGOIRE LECLERC, MD, University Hospital, Orthopedic Surgery; DANIEL WENDLING, PhD, professor, University Hospital J. Minjoz, Besançon, France. Address correspondence to Dr. Prati, University Hospital, Rheumatology, 3 Blvd. Fleming, Besançon 25000, France. E-mail: praticlement@gmail.com.

J Rheumatol 2014;41:973-4; doi:10.3899/jrheum.130865

A gap between toes can be an indication of rheumatoid nodulosis, a relatively benign variant of rheumatic disease.

A 50-year-old woman presented with a 9-month history of a painful spacing of the third and fourth toes on her left foot (Figure 1). The patient had not experienced any trauma. Interdigital palpation found a painful mass. Besides diastasis of the third and fourth metatarsus, the foot radiograph showed no bone destruction or joint damage. Magnetic resonance imaging (Figure 2) showed an intercapito-metatarsal mass corresponding to a collected zone with very little fluid (Figure 2, arrowhead), with thick walls strongly enhanced after gadolinium injection. Two other masses were found on the subcapito-metatarsal areas in relation to the plantar surface of the first and the third metatarsal head (Figure 2, asterisks). These lesions were considered multiple bursitis.

Biological tests revealed positivity of rheumatoid factor and anticitrullinated protein antibodies. A complete radiographic and ultrasonographic investigation did not detect erosion or synovitis. An intralesion injection of steroids had only a transient positive effect, so the patient underwent surgery to remove the interdigital mass, with a pathological feature of a necrosis granuloma with eosinophilic necrotic center and polymorphonuclear neutrophils indicating a rheumatoid nodule. Meanwhile, the patient developed multiple rheumatoid nodules in the forearms, related to rheumatoid nodulosis. Rheumatoid nodulosis is a relatively benign variant of rheumatic disease $^{1}$. This is a rare case of foot rheumatoid nodules ${ }^{2}$ revealing rheumatoid nodulosis.

\section{REFERENCES}

1. Maldonado I, Eid H, Rodriguez GR, Rillo OL, Barcat JA, Reginato AJ. Rheumatoid nodulosis: is it a different subset of rheumatoid arthritis? J Clin Rheumatol 2003;9:296-305.

2. Oloff-Solomon J, Oloff LM, Jacobs AM. Rheumatoid nodulosis in the foot: a variant of rheumatoid disease. J Foot Surg 1984; $23: 382-5$

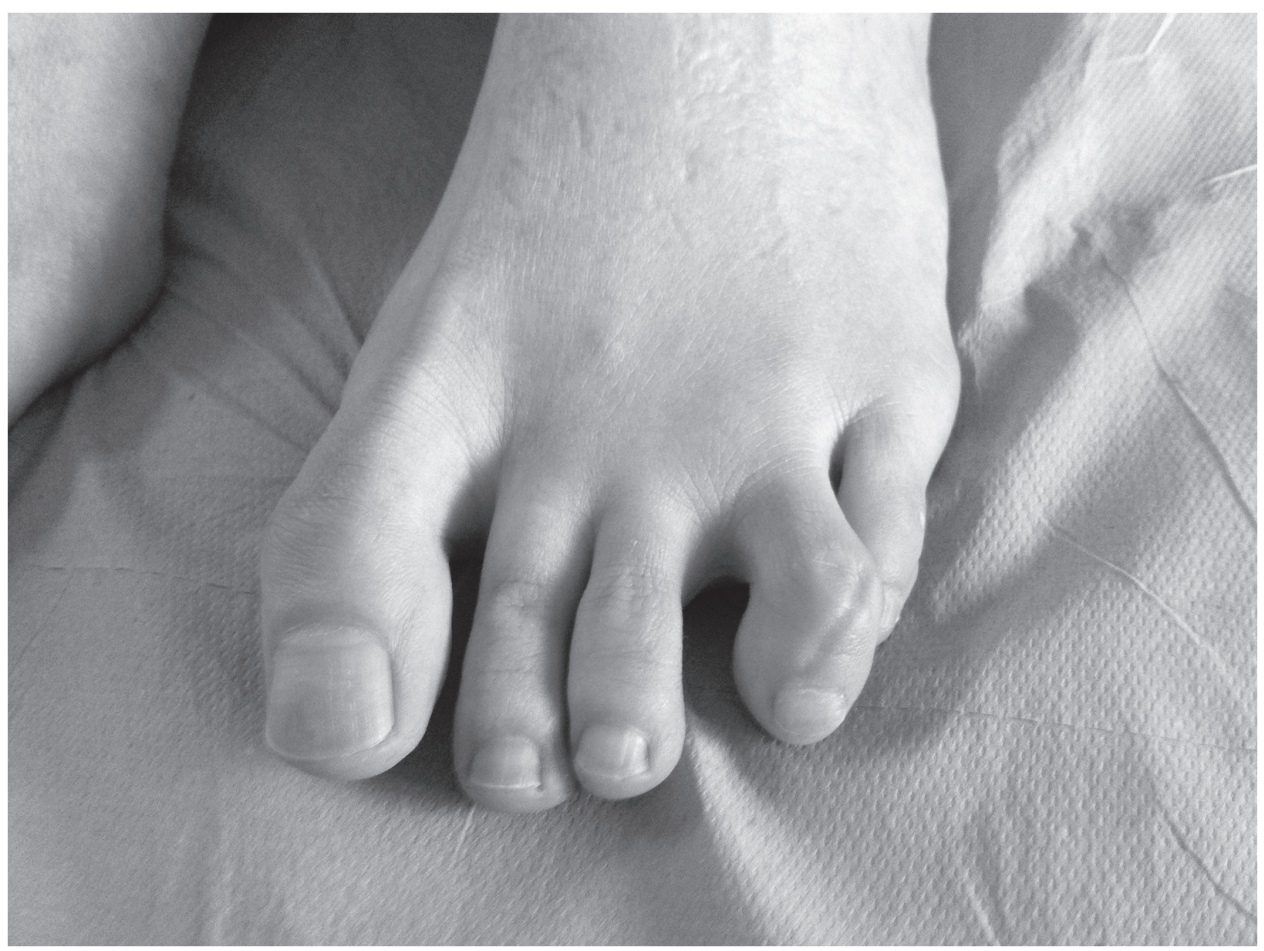

Figure 1. The patient presented with painful spacing of the third and fourth toes of the left foot. 


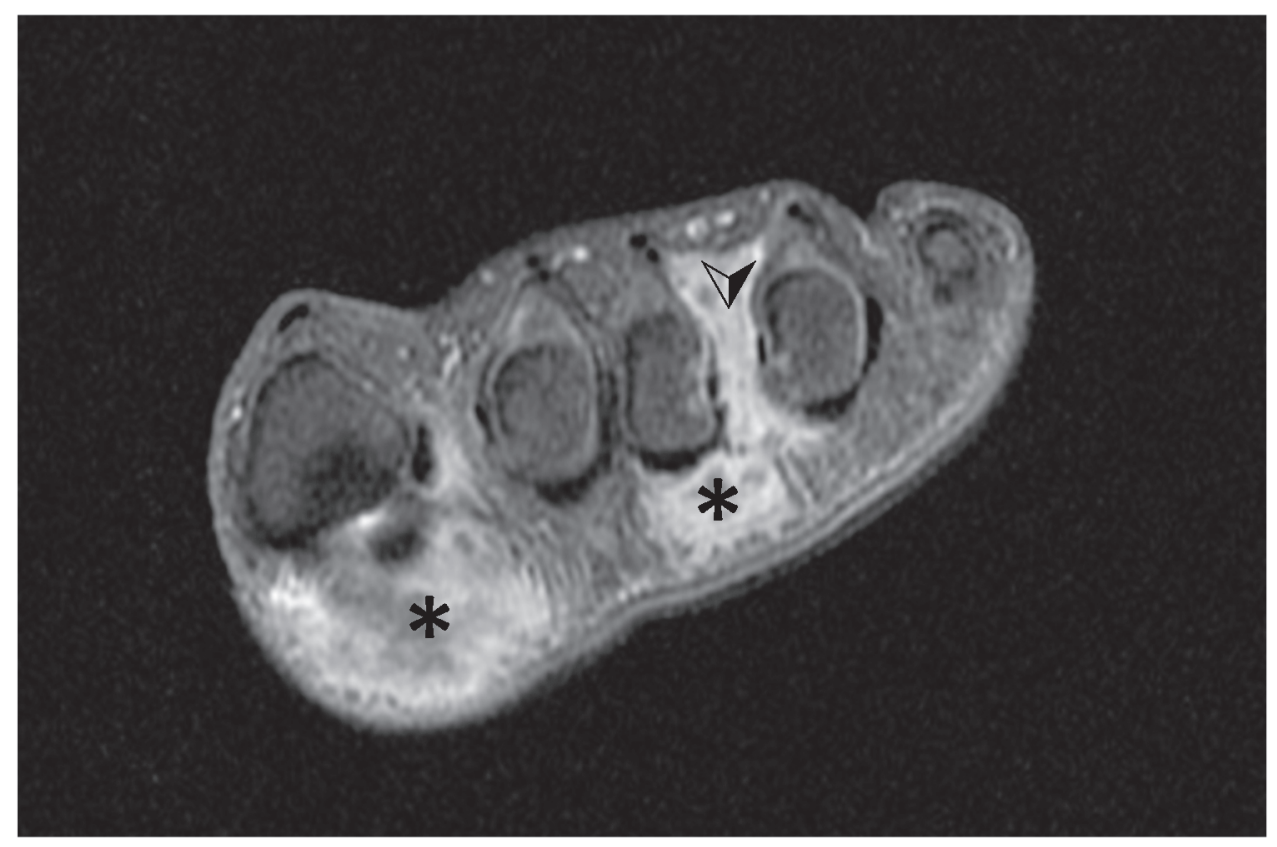

Figure 2. Magnetic resonance imaging showed an intercapito-metatarsal mass corresponding to a collected zone with very little fluid $(\checkmark)$. Two other masses were on the subcapito-metatarsal areas in relation to the plantar surface of the first and the third metatarsal head $(*)$. 